INVESTIGACIÓN/RESEARCH

\title{
INTERCULTURALIDAD EN JUICIO: EL DERECHO DEL INDÍGENA A COMUNICARSE EN SU PROPIA LENGUA
}

Daniela Delgado-Garrido ${ }^{1}$ : Universidad Católica de Temuco. Chile danipaz.delgado@gmail.com

Elsy Curihuinca-Neira: Universidad Católica de Temuco. Chile elsy.curihuinca.n@hotmail.cl

\section{RESUMEN}

El objeto del presente artículo es proporcionar una mirada sistematizada del derecho fundamental que tienen los indígenas a usar su propia lengua en juicios orales penales en Chile. Este derecho será abordado como la facultad que se tiene de escoger en qué idioma declarar independientemente del manejo que se tenga del idioma castellano, debiendo ser asistido por intérpretes en caso de ser necesario. Describiremos como, producto de la alta concentración de población indígena existente, se ha dado cumplimiento a esta garantía a través del surgimiento de la figura del facilitador intercultural, analizando especialmente el contexto mapuche de la novena región y declaraciones prestadas en mapudungun.

PALABRAS CLAVE: Derechos lingüísticos - Propia lengua - Juicio oral en lo penal Intérprete - Facilitador intercultural

\section{INTERCULTURAL ON TRIAL: THE RIGHT OF INDIGENOUS PEOPLE TO COMMUNICATE IN THEIR OWN LANGUAGE}

\begin{abstract}
The objective of this article is to analize the fundamental right a mapuche indian has to use his own language in an oral judgment. It means he will have the right to choose if

\footnotetext{
${ }^{1}$ Autor correspondiente:

Daniela Delgado-Garrido: Licenciada en Ciencias Jurídicas por la Universidad Católica de Temuco, Chile. Experta en derecho indígena.

Correo:danipaz.delgado@gmail.com
} 
he wants his trial in mapudungun or in the official language when declaring, independently of the management he has of the language. It must be assisted by a translator in case it was necessary. Due to a high concentration of mapuche population in Chile it has beebn possible to give this guarantee having an intercultural facilitator specially in the IX region.

KEY WORDS: Linguistic rights - Own language - Oral criminal trials - interpreters intercultural facilitator

\section{INTRODUCCIÓN}

"Al tribunal le resultó poco creíble este testigo desde que declara a través de interpósita persona haciendo ver a los jueces que le era más fácil darse a entender en "mapudungun" 2 .

La oralidad que supone el sistema procesal penal chileno ${ }^{3}$, especialmente en contexto mapuche, ha dejado al manifiesto inconvenientes relacionados con las diversidades de lenguaje y comunicación existente entre los intervinientes del juicio. Un proceso penal efectivo requiere entendimiento entre las partes involucradas, lo que implica, por un lado, el derecho a expresarse en el idioma propio, y por otro, el derecho a comprender en este todo lo dicho en el proceso. Para dar cumplimiento a esta garantía, resulta fundamental la presencia de intérpretes que traduzcan todo lo declarado en audiencias, funcionarios comprensivos de las representaciones sociales y diversidad lingüística de indígenas y operadores judiciales.

En este sentido, abordaremos el derecho fundamental que tiene el indígena a usar su propia lengua en juicio, precisando que debe garantizarse independientemente de la competencia que este tenga del idioma castellano, y que comprende tanto la facultad a declarar en su propia lengua -asistido por la presencia de un intérprete- como a entender en esta, todo lo que se dice durante la audiencia.

En las siguientes páginas, y gracias a la sistematización de información obtenida mediante recopilación de antecedentes bibliográficos y entrevistas cualitativas en profundidad, expondremos conceptos relacionados con el derecho que tiene el indígena a comunicarse en su propia lengua y su concreción como derecho fundamental. A través del análisis de diversas normas de orden interno e internacional, lo dotaremos de un marco jurídico protector que garantice su cumplimiento. Finalmente, describiremos la función que desempeñan los intérpretes

\footnotetext{
2 R.U.C. 0300068481-2 RIT 048/2005. TOP Temuco.

${ }^{3}$ Quisiéramos expresar nuestro agradecimiento a don Horacio Cheuquelaf, Facilitador Intercultural de la Defensoría Penal Mapuche y a doña Jacqueline Caniguan, lingüista de la Universidad Católica de Temuco, quienes amablemente accedieron a participar en las entrevistas realizadas y sus opiniones han constituido el insumo clave de este artículo.
} 
para hacer posible la concreción de éste derecho, precisando la labor realizada por dichos funcionarios y el surgimiento de los facilitadores interculturales en Chile

\section{METODOLOGÍA}

Para el correcto desarrollo de esta investigación, se realizaron varias entrevistas cualitativas, de carácter abierto, en las que se centraron los objetivos perseguidos. El del campo procesal, a cargo de D. Horacio Cheuquelaf (Facilitador Intercultural de la Defensoría Penal Mapuche), uno de los mayores expertos en derechos de los pueblos indígenas en Chile y en el área lingüística a Doña Jacqueline Caniguan, lingüista de la Universidad Católica de Temuco, experta en lenguas indígenas prehispánicas. De la unión de estas entrevistas (cuatro y cinco respectivamente) junto con el marco epistemológico del marco legal de Chile respecto a los derechos lingüísticos indígenas, que las autoras hemos analizado pormenorizadamente, como si de un estudio de caso se tratara, surge la metodología desarrollada para alcanzar las conclusiones finales.

No olvidamos las referencias a estudiosos anteriores en ambos campos convergentes en el presente artículo ya que el marco general, por proceso deductivo-aplicativo, nos sirve de punto de arranque en nuestro estudio.

Saussure influenciado por el sociólogo y antropólogo E. Durkheim (1858-1917), define la lengua como un hecho social, un producto social del lenguaje y un conjunto de convenciones, adoptadas por la comunidad, para permitir el ejercicio de la facultad lingüística entre los individuos ${ }^{4}$ y al lenguaje, como "la totalidad absoluta de los fenómenos lingüísticos" 5 . La importancia que tienen ambos para la comunidad proviene de las vibraciones afectivas que estos comprenden, existe una serie de términos que además de su función denominativa encierran diversos matices de significados y valoraciones $^{6}$, por esto, se ha establecido (versión débil de la hipótesis Sapir-Worf) que al relacionar el lenguaje con el pensamiento y cultura, la estructura de una lengua particular condiciona la forma de pensar de sus hablantes. "Esto significa que los hablantes usan la lengua de una manera diferente dependiendo de lo que hagan; esto es así porque la variación del registro es determinada por la variación de la actividad social que exige su uso" 7 .

\footnotetext{
${ }^{4}$ El estructuralismo. Consultado el 19 de junio de 2011, Disponible en: http://aportes.educ.ar/lengua/nucleo-teorico/recorrido-historico/-la-linguistica-del-sigloxx/el_estructuralismo.php.

${ }_{5}^{5}$ Gil, José María (2001). Introducción a las teorías lingüísticas del siglo XX. Chile: Ril Editores y Melusina Editores, p. 15

${ }^{6}$ Schulte-Herbüggen, Heinz (1963): El lenguaje y la visión de mundo. Santiago de Chile: Universidad de Chile, p. 23.

${ }^{7}$ Agüero, Claudio \& Zambrano, Juan Pablo (2010). Integración metodológica para el estudio del texto de las sentencia penales chilenas, en Revista Convergencia, 17, 54, p. 69-91.
} 
De ahí la necesidad de amparar el derecho a usar la propia lengua ${ }^{8}$ en un proceso judicial, el nacimiento del imputado en una determinada comunidad histórica y usos lingüísticos diferenciados a los del tribunal, hacen necesarios esfuerzos comunicativos entre los diversos sujetos procesales, capacidad de comprender y hacerse comprender, y en caso de ser necesario, ser asistido por intérpretes. Que el indígena pueda comunicarse en su propia lengua en juicio, es un derecho lingüístico, una facultad concedida a los miembros de la comunidad para exigir ante los órganos del Estado y demás miembros de la sociedad su respeto y promoción ${ }^{9}$, forma parte de aquella esfera intangible que gozan las personas por el solo hecho de ser tales y "se sustenta en los principios universales de la dignidad de los humanos y de la igualdad formal de todas las lenguas"10. En este orden de ideas, los derechos lingüísticos son derechos fundamentales tanto en su dimensión individual ${ }^{11}$ como colectiva $^{12}$, no existiendo inconveniente alguno para establecer un marco jurídico protector que garantice su cumplimiento.

\section{ANÁLISIS Y DISCUSIÓN}

En Chile no existe un reconocimiento constitucional de los pueblos indígenas ni de sus derechos lingüísticos. Sin embargo, a través de un análisis armónico de diversas disposiciones lograremos dotar a este derecho de un marco jurídico protector que le haga completamente aplicable.

En el artículo 1, incisos primero y cuarto ${ }^{13}$ de la Carta Fundamental, se instituye una de las funciones más importantes de los derechos humanos; la función legitimadora, poniendo de manifiesto dos elementos centrales desde la perspectiva de los derechos individuales ${ }^{14}$ : el primero, es la visión que existe de los individuos al describirlos como libres e iguales en dignidad y derechos, es decir, todos los hombres, por el sólo hecho de ser tales nacen y conviven con la cualidad de dignos, son trascendentes a la historia,

\footnotetext{
8 En este artículo utilizaremos el concepto de "propia lengua" y no de lengua materna, vernácula, nativa, entre otros, por tratarse de definiciones que presentan connotaciones que exceden nuestra propuesta de trabajo.

${ }^{9}$ Definición estipulativa, elaborada conforme a los objetivos del artículo.

${ }^{10}$ Lingüísticos y educativos. Medidas para implementación del Convenio 169. Consultado el 19 de junio de 2011, Disponible en:

http://redeibchile.blogspot.com/.

11 En conformidad a la Declaración Universal de Derechos Lingüísticos, la dimensión individual es aquel derecho que toda persona tiene a identificarse de manera positiva con su lengua materna y que esta identificación sea aceptada y respetada por los demás.

12 La dimensión colectiva de este derecho corresponde a aquella que se realiza en una comunidad de hablantes o lingüística y es determinante para la identificación de una comunidad, pueblo o grupo.

13 Art. 1 inc. 1 y 4: Las personas nacen libres e iguales en dignidad y derechos. Es deber del Estado resguardar la seguridad nacional, dar protección a la población y a la familia, propender al fortalecimiento de esta, promover la integración armónica de todos los sectores de la Nación y asegurar el derecho de las personas a participar con igualdad de oportunidades en la vida nacional.

14 Nash, Claudio. Los derechos fundamentales: el desafio para el constitucionalismo chileno del siglo XXI. Instituto de investigaciones jurídicas UNAM. Consultado el 19 de junio de 2011, Disponible en: www.juridicas.unam.mx/publica/librev/rev/dconstla/cont/20062/pr/pr30.pdf.
} 
y su destino es realizar un proyecto de vida, con sello singular o propio ${ }^{15}$, y el segundo, es el deber del Estado de dar protección a la población y asegurar el derecho a la participación ${ }^{16}$, traduciéndose en el amparo que debe dar el Estado a los grupos minoritarios que, siendo parte de la nación, no disponen de las mismas herramientas lingüísticas que la mayoría, y por tanto, deben ser atendidos especialmente para no perder sus propias formas de expresión. Por su parte, el artículo 19 n $2^{17}$ establece la igualdad ante la ley, que aplicado al caso concreto, podría interpretarse de la siguiente forma: cuando un sector de la población no comprende el idioma oficial deben realizarse esfuerzos diferentes para hacer efectivos sus derechos, adecuándose el trato a la circunstancia desventajosa.

Claramente lo prohibido por la norma son las diferencias arbitrarias, pues en principio -no hay personas ni grupos privilegiados- sin embargo, cuando los trazos adoptados se hacen considerando las circunstancias fácticas relevantes, las nivelaciones adoptadas son fundadas y por ende, legítimas ${ }^{18}$. Esto, sumado a lo dispuesto en el artículo $19 \mathrm{n}^{\mathrm{o}} 3$ de la Constitución ${ }^{19}$ (la igualdad en la ley) y artículo $6^{20}$ del mismo cuerpo normativo, nos permite afirmar que, independientemente del estatus que el Estado le dé a las lenguas originarias, o de las políticas gubernamentales tendientes a fomentarlas $u$ omitirlas, su uso es una garantía mínima del derecho de defensa y debido proceso y todos los órganos del Estado deben adecuar su comportamiento a estas. El derecho de usar el idioma propio está vinculado al ejercicio de un conjunto de garantías procesales, y que -no olvidemos- gracias al artículo $5^{\circ}$ inciso $2^{21}$ se ve reforzado en sentido formal y material por los diversos tratados internacionales que regulan el respeto, protección y fomento de los derechos lingüísticos.

Por su parte, a nivel legal existen dos formas de regular el derecho al uso de la lengua, primero; a través de una formula genérica (sin delimitarlo a ningún caso especial),

\footnotetext{
${ }^{15}$ Cea, José Luis (2008). Derecho Constitucional Chileno. Santiago de Chile: Ediciones Universidad Católica de Chile.

${ }^{16}$ Nash, Claudio (2011). Los derechos fundamentales: el desafí para el constitucionalismo chileno del siglo XXI. Instituto de investigaciones jurídicas UNAM. Consultado el 19 de junio de 2011, Disponible en:

www.juridicas.unam.mx/publica/librev/rev/dconstla/cont/20062/pr/pr30.pdf.

${ }_{17}$ Art. 19 no 2: "La igualdad ante la ley. En Chile no hay personas ni grupo privilegiado. En Chile no hay esclavos y el que pise su territorio queda libre. Hombres y mujeres son iguales ante la ley. Ni la ley ni autoridad alguna podrán establecer diferencias arbitrarias".

18 Alexy, Robert (2002). Teoría de los Derechos Fundamentales. de Estudios Políticos y Constitucionales, Madrid, p. 395.

${ }^{19}$ Art. 19 n 3 inciso 5: "La igual protección de la ley en el ejercicio de sus derechos. Toda sentencia de un órgano que ejerza jurisdicción debe fundarse en un proceso previo legalmente tramitado. Corresponderá al legislador establecer siempre las garantías de un procedimiento y una investigación racionales y justos".

${ }^{20}$ Art 6: "Los órganos del Estado deben someter su acción a la Constitución y a las normas dictadas conforme a ellas, y garantizar el orden institucional de la República. Los preceptos de esta Constitución obligan tanto a los titulares o integrantes de dichos órganos como a toda persona, institución o grupo. La infracción de esta norma generará las responsabilidades y sanciones que determine la ley".

${ }^{21}$ Art 5 inc $2^{\circ}$ : "El ejercicio de la soberanía reconoce como limitación el respeto a los derechos esenciales que emanan de la naturaleza humana. Es deber de los órganos de Estado respetar y promover tales derechos, garantizados por esta Constitución, así como los tratados Internacionales ratificados por Chile y que se encuentran vigentes".
} 
reconociendo el respeto a la cultura e idioma indígena, y segundo; regulándolo específicamente para contextos judiciales. En el primer caso el artículo 28 de la Ley Indígena $n^{\circ} 19.253^{22}$ (en adelante ley indígena) establece que el uso y conservación de las lenguas es parte del reconocimiento, respeto y protección que debe brindar el estado a la cultura e idioma indígena. En el segundo caso, existen dos disposiciones: el inciso final del artículo 54 de la ley indígena ${ }^{23}$ al disponer que los jueces tienen el deber de aceptar la asistencia de traductor en aquellos casos donde se exija la presencia personal del indígena y éste solicite expresarse en su propia lengua, independientemente del desempeño que tenga del idioma oficial (convirtiéndose en un derecho en sí mismo, un presupuesto indispensable para que la comunidad indígena acceda y participe en los procesos de justicia) y el artículo 291 del Código Procesal Penal24 que sin delimitar la norma a los casos indígenas, restringe explícitamente el derecho a dos supuestos; cuando el interviniente en juicio no pudiere hablar el castellano o no supiere hacerlo (sordomudos y extranjeros por ejemplo).

Saliendo de la normativa local, en el ámbito internacional de los derechos humanos -a diferencia de nuestro monista constitución- existe una amplia normativa que establece principios y derechos específicos para las personas y comunidades indígenas en relación con su derecho al uso de la lengua. Como una forma de simplificar esa compleja preceptiva, la expondremos en tres partes. En primer lugar, el artículo 26 del Pacto Internacional de Derechos Civiles y Políticos ${ }^{25}$ (en adelante PIDCP) establece la prohibición a discriminar por motivos de idioma, raza, color, sexo, religión o cualquier otra condición social. En este caso, el derecho al idioma se garantiza en la misma norma de manera autónoma, imponiendo al Estado la obligación de respetar este principio sin distinguir el origen de la discriminación, en otras palabras; en cualquier caso donde se pretendan realizar diferenciaciones por razones idiomáticas, se estará infringiendo el tratado. ${ }^{26}$ En segundo lugar, los artículos 27 PIDCP 27 y 28 del Convenio 169 de la OIT ${ }^{28}$ establecen que, en aquellos Estados donde existan minorías étnicas, deberá permitirse a los indígenas pertenecientes a estas el empleo de su propio idioma, preservación y promoción de sus lenguas. Estos instrumentos establecen

\footnotetext{
22 Art 28: "El reconocimiento, respeto y protección de las culturas e idiomas indígenas contemplará: a) El uso y conservación de los idiomas indígena, junto al español en las áreas de alta densidad indígena".

23 Art. 54: "El juez encargado del conocimiento de una causa indígena a solicitud de parte interesada y en diligencias o actuaciones en que se requiera la presencia personal del indígena, deberá aceptar el uso de la lengua materna debiendo al efecto hacerse asesorar por traductor idóneo (...)".

24 Art. 291: "Sin embargo, quienes no pudieren hablar o no lo supieren hacer en el idioma castellano, intervendrán por escrito o por medio de intérpretes".

25 Art 26: "Todas las personas son iguales ante la ley y tienen derecho sin discriminación a igual protección de la ley. A este respecto, la ley prohibirá toda discriminación y garantizará a todas las personas protección igual y efectiva contra cualquier discriminación por motivos de raza, color, sexo, idioma, religión, opiniones politicas o de cualquier índole, origen nacional o social, posición económica, nacimiento o cualquier otra condición social".

${ }^{26}$ En este sentido encontramos los artículos 1.1 de la Convención Americana sobre Derechos Humanos (en adelante CADH), 2.2 del Pacto Internacional de Derechos Económicos, Sociales y Culturales y 2.1 de la Convención Internacional de los Derechos del Niño.

27 Art 27: "En los Estados en que existan minorías étnicas, religiosas o lingüísticas, no se negará a las personas que pertenezcan a dichas minorías el derecho que les corresponde, (...) y a emplear su propio idioma".

28 Deberán adoptarse disposiciones para preservar las lenguas indígenas de los pueblos interesados y promover el desarrollo y las prácticas mismas.
} 
normas protectoras orientadas a lograr la igualdad idiomática y permiten que si una persona no entiende o no desea expresarse en el idioma oficial del Estado, tenga el derecho a utilizar su propia lengua ${ }^{29}$. En tercer lugar y específicamente como garantía procesal, los artículos 8.2.a de $\mathrm{CADH}^{30}$ y 14.3.f del PIDCP ${ }^{31}$ consagran el derecho a ser asistido en juicio por intérprete o traductor cuando no se comprenda o desee utilizar el idioma oficial, volviéndose la presencia del intérprete un derecho irrenunciable que permite la comunicación de los diversos intervinientes, concretando el derecho a defensa en juicio.

En definitiva, el derecho al uso de la propia lengua se encuentra garantizado en la normativa internacional no sólo como una prohibición a discriminar en general, sino que también se consagra específicamente en contextos judiciales como una garantía del proceso.

\subsection{Derecho a intérprete en el juicio}

En nuestro país y debido a la alta concentración de población indígena ${ }^{32}$, se ha dado cumplimiento al derecho en cuestión -usar la lengua propia en juicio- a través de las declaraciones prestadas por interpósita persona. La Ley Indígena usa el término de traductor, y el Código Procesal Penal se refiere a intérprete, pero, ¿qué son la traducción e interpretación?

Traducir viene del latín traducĕre, hacer pasar de un lugar a otro, en otras palabras, es "expresar en una lengua lo que está escrito o se ha expresado antes en otra" 33 . La traducción consiste en efectuar un cambio de forma, reemplazando la forma de la lengua de origen por la forma de la lengua de recepción ${ }^{34}$. Constanza Gerdyng la ha definido como:

una operación de transferencia ínter lingüística que consiste en interpretar el sentido de un texto de origen y producir un texto de llegada buscando establecer una relación de equivalencia entre ambos, de acuerdo con los

\footnotetext{
29 También existen normas que abordan genéricamente este derecho, tal es el caso del artículo 13.1 de la Declaración Universal de Derechos de los Pueblos Indígenas, y los numerales 5 y 6 de las Principales Orientaciones de la Declaración universal sobre la Diversidad Cultural, que reconocen el derecho que tienen los pueblos indígenas a usar, promover y transmitir las lenguas, sin limitaciones de ningún tipo. 30 Art 8.2. a) "Derecho del inculpado de ser asistido gratuitamente por el traductor o intérprete, si no comprende o no habla el idioma del juzgado o tribunal".

31 Art. $14.3 \mathrm{f}$ ) "A ser asistida gratuitamente por un intérprete, si no comprende o no habla el idioma empleado en el tribunal".

32 En el Censo del 2002 la población que se considera perteneciente a grupos étnicos es de 692.192 equivalente al 4,6\% de la población total de Chile, de los cuales el 87,31\% corresponde a la etnia mapuche.

33 Real Academia Española (2001). Diccionario de la lengua española (22. ed.). Disponible en: www.rae.es. (Consultado el 13 de junio de 2011).

${ }^{34}$ Larson, Mildred L. (1989). La traducción basada en el significado. Un manual para el descubrimiento de equivalencia entre lenguas. Buenos Aires: Editorial universitaria de Buenos Aires (Versión Española Donald H. Burns y Rodolfo von Moltke).
} 
parámetros inherentes a la comunicación dentro de las restricciones propias de las lenguas. La traducción se realiza, por lo general, en forma escrita, a diferencia de la interpretación, que es una actividad de transferencia ínter lingüística oral o gestual" 35 . En este sentido, el traductor es un especialista de la comunicación, un mediador interlingüístico, que reexpresa documentos escritos de una lengua a otra $(\ldots)^{36}$. Es importante destacar que el proceso de traducción no excluye el de interpretación, este último siempre será necesario para encontrar y dar un sentido al texto, resultando ser más que un opuesto, su complemento.

Por su parte, interpretar viene de interpretāri, traducir de una lengua a otra, especialmente cuando se hace oralmente ${ }^{37}$. La interpretación es la actividad profesional consistente en establecer, en forma simultánea o consecutiva, unidireccional o bidireccional, la comunicación oral o gestual entre dos o más interlocutores que no hablan la misma lengua ${ }^{38}$.

Atendida la oralidad que supone la labor de interpretar, y sumado a los objetivos del presente artículo se desarrollará especialmente la labor del intérprete en juicios penales, por tratarse -reiteramos- de audiencias eminentemente orales. El intérprete es un especialista de la comunicación ${ }^{39}$ que sirve de mediador entre dos o más interlocutores de idiomas ${ }^{40}$ y que en contexto judicial penal, podemos definir como un profesional establecido con anterioridad al juicio en que intervendrá, de carácter imparcial, capacitado y con experiencia, que interpreta de manera veraz y completa todo lo que se manifiesta en audiencia durante los procedimientos del tribunal, manteniendo el registro, tono, y contenido de lo que se dice con estricto apego a las normas que le rigen ${ }^{41}$.

En Chile esta labor no ha sido regulada ni institucionalizada. A pesar de las exigencias que impone el actual sistema oral en lo penal ${ }^{42}$, el poder judicial no cuenta con

${ }^{35}$ Gerding, Constanza (2008). Traducción, terminología de la traducción. Chile: Universidad de Concepción.

36 Ibid.

${ }^{37}$ Real Academia Española. (2001). Diccionario de la lengua española (22. ed.). Consultado el 13 de junio de 2011, Disponible en: $\underline{w w w . r a e . e s . ~}$

${ }^{38}$ Gerding, Constanza: Traducción, terminología de la traducción. Ob. Cit.

${ }^{39}$ Ibid.

${ }^{40}$ Antecedentes históricos dan cuenta de la existencia de personas indígenas oradoras. Debido al manejo que estos poseían del mapudungun como de la lengua castellana destacaba su capacidad discursiva en parlamentos. Si se desea profundizar en el tema ver Guevara, Tomás \& Mankelef, Manuel (2002). Kiñemufütrokiñcheñi piel Historias de familia/ siglo XIX. Centro de Estudios y Documentación Mapuche Liwen. Santiago de Chile: CoLibris Ediciones.

${ }^{41}$ Judicatura de Rhode Island: Preguntas frecuentes sobre los intérpretes del tribunal. Consultado el 19 de junio de 2011, Disponible en:

www.courts.ri.gov/Interpreters/SpanishVersion/PDF/FAQ.pdf.

42 Art 291 del Código Procesal Penal: “Oralidad. La audiencia del juicio se desarrollará en forma oral, tanto en lo relativo a las alegaciones y argumentaciones de las partes como a las declaraciones del acusado, a la recepción de las pruebas $y$, en general, a toda intervención de quienes participaren en ella.

Las resoluciones serán dictadas y fundamentadas verbalmente por el tribunal y se entenderán notificadas desde el momento de su pronunciamiento, debiendo constar en el registro del juicio". 
intérpretes en lenguas indígenas, han sido la Defensoría Penal y Ministerio Público locales $^{43}$ (debido a las demandas que conlleva la atención permanente de personas indígenas en general, y mapuche en particular) los que han debido incorporar a sus respectivas unidades de trabajo expertos en el área, aunque denominándolos de una particular forma: facilitadores interculturales.

La figura del facilitador intercultural tiene su origen en agosto del año 2001, luego de la implementación de la reforma procesal penal chilena en la novena región. Desde el inicio de ésta, se observó que la defensa de personas mapuche presentaba aspectos que diferenciaban la labor de los defensores en relación al resto de los imputados, la existencia de demandas territoriales y diferencias culturales reflejaban barreras idiomáticas, y sobre todo, la necesidad de crear una oficina especializada denominada Defensoría Mapuche (en adelante DPM), además de la presencia de un traductor o intérprete que pudiera servir de puente entre los diversos intervinientes del proceso ${ }^{44}$.

El Facilitador Intercultural es una persona que trabaja tanto en Defensoría Penal como Ministerio Público, hablante de mapudungun y que se preocupa de la correcta atención al mapuche que llegue a sus dependencias, respetando lo más posible sus costumbres, usos, lengua y tradiciones. Su denominación se debe a que facilitan las relaciones entre distintas culturas ${ }^{45}$.

Debido a que ha sido el facilitador intercultural de la DPM quien más tiempo se ha desarrollado en el cargo, precisaremos la función que éste desempeña en oficinas de la DPM y audiencias judiciales.

La labor del facilitador intercultural en las dependencias de la defensoría especializada es imprescindible cuando el imputado o acusado y su familia no se expresan en idioma castellano, y, por su parte, el abogado defensor y su equipo no comprenden el idioma propio de este ni su representación social. Su presencia es necesaria para que el abogado pueda llevar a cabo una buena defensa, lo que se ve manifestado "en el juicio oral, donde la ubicación e inclusión de testigos y, en general, la búsqueda de medios probatorios habrá de hacerse dentro del marco humano y material de la comunidad indígena y en el espacio de su cultura" 46 . La función que desempeña este funcionario, recibiendo y analizando los casos, viajando a las comunidades de los involucrados, visitando a los imputados en prisión y capacitando a los defensores entre otras, es un eslabón fundamental para la concreción del debido proceso. En este sentido, cuando el indígena se ve involucrado en el sistema penal, no comprende los códigos lingüísticos del castellano,

\footnotetext{
${ }^{43}$ En este artículo nos referiremos solamente a la Defensoría Penal, debido a que ha sido esta institución la que ha iniciado y desarrollado esta función. Paralelo a ello, el Ministerio Público también cuenta con un funcionario hablante del mapudungun pero que trabaja como intérprete sólo ocasionalmente.

44 López, Jaime (2006). Experiencia chilena de la defensa penal de los imputados mapuches en un sistema acusatorio. Boca del río, Veracruz: En Memoria del foro Defensoría Pública Bilingüe.

${ }^{45}$ Cuenta pública de la Fiscalía. Consultado el 1 de junio de 2011, Disponible en: $\underline{\text { www.fiscaliadechile.cl/Fiscalia/index.do y Defensoría, disponible en: www.dpp.cl/ }}$

46 López, Jaime (2006). Experiencia chilena de la defensa penal de los imputados mapuches en un sistema acusatorio. Ob. Cit.
} 
ni los tecnicismos propios del lenguaje judicial -extraños para cualquier persona que no pertenece a éste- resultando imprescindible la labor del facilitador intercultural que actúa como nexo entre el indígena que no puede expresarse en castellano -o no desea hacerlo-, y el resto de los intervinientes del juicio que, viceversa, tampoco comprenden su propia lengua.

Como una forma de exponer las implicancias y autopercepción del trabajo realizado por don Horacio Cheuquelaf (facilitador Intercultural de la DPM) especialista en lengua y cultura mapuche ${ }^{47}$, este expone ${ }^{48}$ :

Yo soy un rañiñelwe, una especie de puente, de comunicación entre personas que principalmente no se den a conocer bien por hablar en mapudungun, lo que trato de hacer es un acercamiento del tema más técnico, de la defensoría con aquellas personas. La vinculación directa está con los imputados, por causas donde se involucre el aspecto cultural". "Lo que yo hago es facilitar las relaciones entre el imputado y el defensor, entre el defensor y el imputado, entre los que forman parte de la familia del imputado y la defensoría.

Por otra parte, en audiencias judiciales el facilitador intercultural actúa como intérprete de tribunal, manteniendo el registro, tono, y contenido de los dichos del indígena y de operadores judiciales, sin agregar ni omitir nada. Su labor sólo consiste en facilitar la participación en el proceso judicial, no explica, resume ni da consejos legales, como tampoco presenta peritajes lingüísticos. A este respecto, expondremos algunos casos en los que se ha hecho uso de su presencia:

CUARTO: Que, el Ministerio Público, con la finalidad de acreditar los cargos, se valió de prueba testimonial, documental, pericial y material, las que en su mayoría también hizo suyas la defensa. De este modo, condujo a estrados a la madre del encausado y testigo presencial de los hechos, (...), quién fue asistida por los facilitadores interculturales bilingues Lidia Antilef Mariqueo y Horacio Cheuquelaf, proporcionados tanto por el Ministerio Público como por la Defensa $^{49}$.

"La Testimonial se conformó con los dichos de: (...) quien expuso asistido por dos intérpretes interculturales, de la Fiscalía y de la Defensa"50.

\footnotetext{
${ }^{47}$ Con la entrevista se busca establecer una apertura de canales que pueda crear la efectividad práctica de comunicación interpersonal, este método nos proporcionó información detallada que tiene el informante respecto de su cargo y experiencia.

${ }^{48}$ Para obtener este testimonio se realizó una entrevista cualitativa en profundidad a don Horacio Cheuquelaf. Entenderemos que este tipo de entrevista es aquella realizada a través de reiterados encuentros cara a cara entre el entrevistador y los informantes, encuentros dirigidos hacia la comprensión de las perspectivas que los informantes tienen respecto de sus vidas, experiencias o situaciones, tal como las expresan en sus propias palabras. Taylor, S. J. \& Bogan, R. (1986). Introducción a las metodologías cualitativas de investigación. Buenos Aires: Paidós.

${ }^{49}$ R.U.C. 0100017834-5; R.I.T: 009 / 2002 TOP Temuco.

50 R.U.C. 0600106737 - 9; R.I.T. 129/2006 TOP Temuco.
} 
"SEXTO: Que, de conformidad con lo señalado por la defensa durante el juicio, la que se hizo asesorar por los intérpretes de las lenguas castellana y mapudungún, Anselmo Rapiman Melio por el acusado y Lidia Antilef Maliqueo por la fiscalía"51.

"SÉPTIMO: Que, el Ministerio Público, con la finalidad de demostrar su pretensión, se valió de las siguientes pruebas que rindió durante la secuela del juicio oral:

Mediante la testimonial expusieron: 1.- L.C.M.N., quien interrogada por intermedio de la facilitadora intercultural, juró decir la verdad"52.

Como se observa, la labor del intérprete -facilitador intercultural cuando se trata de hablantes originarios- resulta fundamental para la debida comunicación entre los intervinientes y el tribunal. Sin embargo, esta función no ha estado exenta de críticas, se ha cuestionado "la participación de traductores [en juicio] por cuanto descontextualizaría el idioma indígena de su entorno cultural y cosmovisión" 53. Sin embargo, dicho reparo merece a lo menos tres observaciones: en primer lugar, la intervención del facilitador intercultural en juicio logra precisamente contextualizar el idioma indígena, le da cabida en un espacio donde el castellano predomina. En segundo lugar, dar sentido a tal afirmación significaría dejar reservado el uso de la lengua a un espacio muy reducido, a los comunitarios solamente, lo que conllevaría a postular a su fosilización e incluso, desaparición54. Por último, la figura del facilitador no puede ser reducida a la mera traducción, como ya fue señalado él es un intérprete, su campo de trabajo es esencialmente oral, además, su amplio dominio del idioma y sensibilidad lingüística55, el conocimiento que posee de los patrones culturales diferenciados y en la mayoría de los casos, su ascendencia indígena, le permiten ser un nexo entre los distintos operadores judiciales; defensores, fiscales, jueces por un lado, y el indígena y su familia, comunidad o entorno social por otro.

Retomando, también existen casos donde -lamentablemente- sólo en apariencia se ha respetado el derecho a declarar por medio de intérpretes, pues aunque se ha les ha permitido a los intervinientes declarar en mapudungun, en el momento que el juez ha debido valorar dichos mensajes los ha desestimado en razón de que el indígena habría

\footnotetext{
51 R.U.C. 0300201219 - 6; RIT 021/2004 TOP Temuco.

52 R.U.C. 11005505 42-0: RIT 234-11 TOP Temuco.

53 Faundez, Juan Jorge (2001). Reforma penal y derechos del pueblo mapuche en Revista Liwen $\mathrm{n}^{\mathrm{o}}$ 5, $\mathrm{p}$. 36.

54 En palabras de la lingüista Jacqueline Caniguan, "la lengua tiene muchas funciones sociales, dejar las lenguas reducidas a un espacio puramente ritual ha sido uno de los factores de su desaparición. Al contrario, cuando en diversas partes del mundo se ha querido revitalizarlas, entre otras medidas se han promovido sus funciones, a la cotidianeidad y al mayor número de espacios posibles". En igual sentido Albarracín, Lelia Inés (2003). Multiculturalidad y plurilingüismo: el derecho al uso de la propia lengua, en VI Jornadas internacionales de educación "Educación: Complejidad, Rupturas y Desafíos", Facultad de Ciencias de la Administración, Universidad Nacional de Entre Ríos, Ciudad de Concordia.

55 Cualidad de un traductor(a) que se manifiesta a través del sentido de la intuición con respecto a la lengua, que le exige conocimientos de los usos lingüísticos, actitud para captar los matices sutiles y conciencia de las expectativas lingüísticas que tienen los destinatarios. Es evidente cuando se requiere realizar una adaptación a la traducción de un cliché o una metáfora Gerding (2008, p. 40)
} 
logrado manifestar ciertas palabras en castellano, pasando por alto lo siguiente: que una persona pueda responder a unas cuantas frases en castellano no significa que maneje completamente ese idioma, como tampoco, que entienda todas las connotaciones, simbolismos y valores envueltos en dichas expresiones, no necesariamente se está comunicando como quisiera.

"Al tribunal le resultó poco creíble este testigo desde que declara a través de interpósita persona, haciendo ver a los jueces que le era más fácil darse a entender en "mapudungun"; sin embargo, cuando es preguntado por el tribunal, respondió fluidamente en Castellano" 56.

No es suficiente aceptar las declaraciones prestadas a través de intérprete si estas no serán valoradas de la igual forma que aquellas otorgadas por personas que no requieren de dicha asistencia. Los hechos deben ser tratados por el juez como construcciones lingüísticas, unidades culturales. El tribunal no se entiende directamente con los hechos brutos, sino con proposiciones o enunciados relativos a representaciones cognoscitivas ${ }^{57}$, por eso, la presencia del intérprete se vuelve un derecho irrenunciable que garantiza la defensa ${ }^{58}$, "este derecho implica no sólo la facultad de declarar en el idioma materno, con la presencia de un traductor que le permita entender la declaración al resto de los intervinientes que no conocen el idioma, sino que incluye también el derecho a que un traductor le permita entender en su idioma todo lo que se dice durante la audiencia ${ }^{59}$.

\section{CONCLUSIONES}

Conforme a la tesis débil de Sapir-Whorf 60 , el nacimiento de un individuo en una determinada comunidad histórica influye en su manera de comprender el mundo, en la asimilación de los patrones normativos comunitarios básicos. Con la lengua éste no sólo verbaliza y transmite sus pensamientos, sino que además encausa y guía su actividad mental. Por esto, es imprescindible que se reconozca el derecho fundamental que tiene el indígena a usar su propia lengua en juicio.

Este artículo ha ofrecido una mirada sistematizada de las disposiciones legales existentes y documentos elaborados por diversos autores que directa o indirectamente han abordado la materia. El análisis de las normas de carácter interno (a nivel constitucional y legal) y externo (tratados internacionales), nos permitió establecer que el derecho a usar la propia lengua se encuentra plenamente garantizado. Sin embargo, queda de manifiesto la necesidad de contar con más intérpretes judiciales en Chile,

\footnotetext{
56 R.U.C. 0300068481-2 RIT 048/2005. TOP Temuco.

57 Alfaro, Christian \& Agüero, Claudio (2004/2005). Sobre las ficciones en el discurso jurídico-penal de las sentencias: el caso chileno, en Revista Telemática de Filosofía del Derecho no 8, p. 1-23.

58 Irigoyen, Raquel: Fundamentos jurídicos para una justicia multilingüe en Guatemala. Consultado el 19 de junio de 2011, Disponible en: www.bibliojuridica.org/libros/2/740/11.pdf.

59 Defensoría Penal, Oficio $\mathrm{n}^{\circ}$ 177: Instruye sobre criterios generales para otorgar una atención especializada a personas indígenas, Santiago 08 de julio 2003.

60 Schulte-Herbüggen, Heinz: El lenguaje y la visión de mundo. Ob. Cit.
} 
estos son quienes posibilitan la comunicación entre los diversos intervinientes de un juicio. Es imperiosa la institucionalización y regulación de su cargo debido a que son los canales que concretan el derecho a defensa. Si asumimos que la facultad de usar la propia lengua en juicio es un derecho por ser el medio que el imputado tiene para comunicarse, verbalizar y transmitir sus declaraciones, es imprescindible que en la producción del discurso judicial -sentencia- se revele una valoración efectiva de las declaraciones efectuadas a través de intérpretes. Si bien los operadores judiciales (especialmente los jueces) no tienen la obligación de conocer y comprender la lengua indígena61, resulta fundamental que las declaraciones prestadas por interpósita persona sean valoradas de la misma manera que aquellas otorgadas por personas que no requieren de esta asistencia. Así, se debe capacitar a los funcionarios judiciales respecto de las implicancias que conllevan la diversidad y los contenidos idiomáticos y socioculturales abarcados por una lengua.

Finalmente, y asumiendo la diversidad lingüística existente e implicancias jurídicas que esta tiene, nos sentimos comprometidas a profundizar en trabajos venideros.

\section{REFERENCIAS}

Agüero, C. \& Zambrano, J. P. (2010). Integración metodológica para el estudio del texto de las sentencias penales chilenas, en Revista Convergencia n ${ }^{\mathrm{o}} 17,54$, p. 69-91.

Albarracín, L. I. (2003): Multiculturalidad y plurilingüismo: el derecho al uso de la propia lengua, en VI Jornadas internacionales de educación "Educación: Complejidad, Rupturas y Desafíos", Facultad de Ciencias de la Administración, Universidad Nacional de Entre Ríos, Ciudad de Concordia (Argentina).

Alfaro, C. \& Agüero, C. (2004/2005). Sobre las ficciones en el discurso jurídico-penal de las sentencias: el caso chileno, en Revista Telemática de Filosofía del Derecho no 8, p. 1-23.

Alexy, R. (2002). Teoría de los Derechos Fundamentales. Madrid: Centro de Estudios Políticos y Constitucionales.

Cea, J. L. (2008). Derecho Constitucional Chileno. Chile: Ediciones Universidad Católica de Chile.

Del Valle, C. (2004). Los indígenas en las relaciones de sucesos españoles. Representación y memoria desde la interculturalidad, en Revista Zer n 16, p. 121-136.

Escalante, L. (2011). Los derechos políticos-electorales del ciudadano mexicano habitante y residente en Baja California. Consultado el 30 de abril de 2011, Disponible en: www.bibliojuridica.org/libros/4/1784/22.pdf.

${ }^{61}$ Esto sin perjuicio que consideramos que el juez debe comprender la lengua y representación sociocultural del indígena que declara en el proceso. 
Faundez, J. J. (2001). Reforma penal y derechos del pueblo mapuche, en Revista Liwen $\mathrm{n}^{\mathrm{o}} 5$.

Gerding, C. (2008). Traducción, terminología de la traducción. Chile: Universidad de Concepción.

Guevara, T. \& Mankelef, M. (2002). Kiñemufütrokiñcheñi piel Historias de familia/ siglo XIX.. Santiago de Chile: Centro de Estudios y Documentación Mapuche Liwen. CoLibris Ediciones.

Gil, J. M. (2001). Introducción a las teorías lingüísticas del siglo XX. Chile: Ril Editores y Melusina Editores.

Horvitz, M. I. y López, J. (2007). Derecho Procesal Penal Chileno. Tomo I. Santiago de Chile: Editorial Jurídica de Chile.

Irigoyen, R. (2011). Fundamentos jurídicos para una justicia multilingüe en Guatemala. Consultado el 15 de mayo de 2011, Disponible en: www.bibliojuridica.org/libros/2/740/11.pdf.

Larson, M. L. (1989). La traducción basada en el significado. Un manual para el descubrimiento de equivalencia entre lenguas (Versión Española Donald H. Burns y Rodolfo von Moltke). Buenos Aires: Editorial universitaria de Buenos Aires.

López, J. (2006). Experiencia chilena de la defensa penal de los imputados mapuches en un sistema acusatorio, en Actas de la Memoria del Foro Defensoría Pública Bilingüe, Boca del río, Veracruz.

Nash, C. (2011). Los derechos fundamentales: el desafío para el constitucionalismo chileno del siglo XXI. Consultado el 30 de mayo de 2011Disponible en:

www.juridicas.unam.mx/publica/librev/rev/dconstla/cont/20062/pr/pr30.pdf.

REA: Diccionario de la lengua española(2001). (22. ed.). Consultado el 3 de junio de 2011, Disponible en: $\underline{\text { www.rae.es. }}$

Schulte-Herbüggen, H. (1963). El lenguaje y la visión de mundo. Santiago de Chile: Universidad de Chile.

Taylor, S. J. \& Bogan, R. (1986). Introducción a las metodologías cualitativas de investigación. Buenos Aires: Paidós.

Valadés, D. (2011). El derecho de la lengua. Instituto de investigaciones jurídicas UNAM. Disponible en: www.juridicas.unam.mx/publica/librev/rev/trcons/cont/18/pr/pr11.pdf.

(Consultado el 30 de mayo de 2011) 
Valadés, D. (2011). El derecho de la lengua. Pensamiento Constitucional. Fondo Editorial Pontificia Universidad Católica del Perú. Consultado el 30 de mayo de 2011, Disponible en:

http://revistas.pucp.edu.pe/pensamientoconstitucional/sites/revistas.pucp.edu.pe.p ensamientoconstitucional/files/images/05Pensamiento12Valadespdf. (Consultado el)

\section{Daniela Delgado-Garrido}

Licenciada en Ciencias Jurídicas por la Universidad Católica de Temuco, Chile. Experta en derecho indígena.

\section{Elsy Curihuinca-Neira}

Licenciada en Ciencias Jurídicas por la Universidad Católica de Temuco, Chile. Experta en derecho indígena. 